\title{
Experimental study of horizontal impact forces acting on equipment of thick sheet rolling stands during rolling
}

\author{
Anatoliy Ishchenko ${ }^{1}$, Viktor Artiukh, ${ }^{2, *}$ and Vladlen Mazur ${ }^{3}$, Albina Calimgareeva ${ }^{4}$ and \\ Miroslava Gusarova ${ }^{5}$ \\ ${ }^{1}$ Pryazovskyi State Technical University, Universytets'ka, 7, Mariupol, 87500, Ukraine \\ ${ }^{2}$ Peter the Great St.Petersburg Polytechnic University, Polytechnicheskaya, 29, St. Petersburg, \\ 195251, Russia \\ ${ }^{3}$ LLC «Saint-Petersburg Electrotechnical Company», Pushkin, Parkovaya, 56, Saint-Petersburg, \\ 196603, Russia \\ ${ }^{4}$ South Ural State University (National Research University), Nizhnevartovsk Branch, Mira str., 9, \\ 628600, Russia \\ ${ }^{5}$ Tyumen Industrial University, Volodarskogo str., 38, Tyumen, 625000, Russia
}

\begin{abstract}
Technical aspects, methods and results of experimental studies of reversing rolling stands details horizontal accelerations of thick sheet rolling mills 3000 and 3600 are shown. Sequence of horizontal movements of bottom work roll with chocks in windows of housings during normal metal-in, steady rolling and metal-out is given. Usage of obtained experimental data and calculation of horizontal forces of work rolls chocks impacts against housings provided execution of stress calculations of technical solutions for increase of rolling stands durability.
\end{abstract}

\section{Introduction}

Horizontal impact forces acting on equipment of thick sheet rolling stands during rolling influence quality of rolled metal and durability of rolling equipment [1]. High values of contact stresses and deformations arise in details of thick sheet rolling stands [2, 3]. Stabilization of work of main drive lines of thick sheet rolling mills during increase of their productivity is important task [4-6]. Theoretical data of dynamic loading of rolling stands (that was proved experimentally) was used to make stress calculations of technical solutions for reduction of impact loads [7-12].

\section{Formulation of task}

Experimental studies of accelerations of thick sheet rolling stands details require usage of expensive equipment that is why more popular solution is direct measurement of forces of horizontal impacts of rolls chocks against housings and control of their displacements (movements). Machining of rolling stands details usually must be done to install sensors for

\footnotetext{
${ }^{*}$ Corresponding author: artiukh@mail.ru
} 
direct measurements of forces of horizontal impacts but it can reduce durability of details. Therefore accelerations measurements of details are popular because sensors are installed on details prepared surfaces without their significant machining. Analysis of measured horizontal accelerations and displacements during unsteady and steady rolling helps to visualize dynamics of rolling stands.

Objectives of this paper:

- $\quad$ explain technical aspects and methods of experimental measurements of horizontal accelerations and displacements of work rolls (WRs) chocks of rolling stands of thick sheet rolling mills 3000 and 3600 [13-15];

- detailed analysis of obtained experimental measurements of horizontal accelerations and displacements of details of the thick sheet rolling mills;

- describe usage of the experimental measurements for increase of rolling equipment durability.

\section{Materials and Methods}

Specialists from Pryazovskyi State Technical University (PSTU, Ukraine) and Peter the Great St. Petersburg Polytechnic University (SPbPU, Russian Federation) fulfilled:

- $\quad$ experimental measurements of horizontal accelerations and displacements of details of rolling stands of thick sheet rolling mills 3000 and 3600 (Ukraine);

- detailed analysis of obtained experimental measurements;

- $\quad$ projects of technical solutions for increase of rolling equipment durability.

Analog-to-digital converter (ADC) E14-440, computer, inertial sensors, displacement sensors, etc. were used during the experiments (fig. 1). Inertial sensors FLXL 150 AQC (mass is around 12 grams, measurement limits are from $0 \mathrm{~m} / \mathrm{s}^{2}$ to $50 \times 9.81 \mathrm{~m} / \mathrm{s}^{2}$, sensitivity is equal to $38 \mathrm{mB} / \mathrm{g}$ ) were used to measure accelerations during displacements of WRs chocks in housing windows.

Displacement sensors are beams of equal resistance with glued on them strain gauges (resistance of each is $200 \mathrm{ohms}$ ) switched in bridge circuit. Signals from sensors via ADC were recorded into computer database.

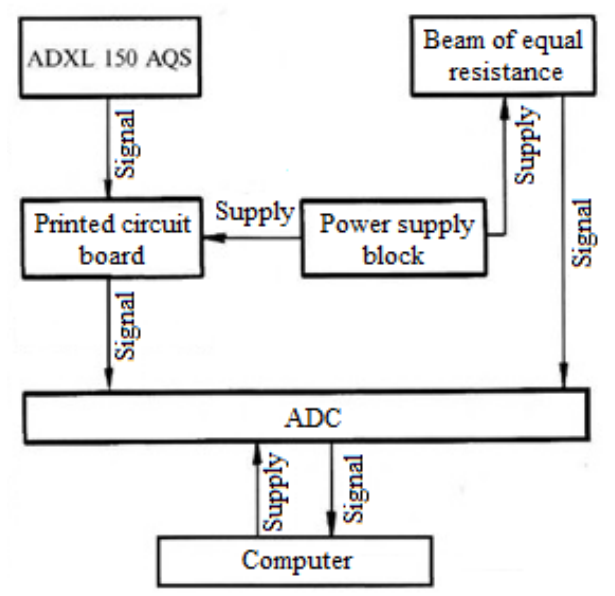

Fig. 1. Connection diagram of measurement equipment

Scheme of sensors installation on operator side (OS) is shown on fig. 2. Sensors were similarly installed on drive side (DS). 


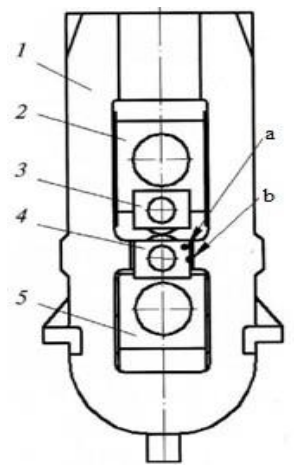

1 is rolling stand housing;

2 is top back-up roll chock;

3 is top work roll chock;

4 is bottom work roll chock;

5 is bottom back-up roll chock;

a is place of acceleration sensor

installation;

$\mathrm{b}$ is place of displacement sensor

installation

Fig. 2. Scheme of sensors installation on rolling stand

Experiment measurements of horizontal accelerations and displacements of bottom work roll (BWR) chocks were done during rolling. E.g., measured data on thick sheet rolling mill 3000 during rolling of slab with section $228.1 \mathrm{~mm} \times 2027 \mathrm{~mm}$ (length $2550 \mathrm{~mm}$ ) made from steel grade S355 is shown on fig. 3. Part of that data during pass \#3 is shown on fig. 3 .

According to fig. 4 maximum values of BWR chocks horizontal accelerations are $-82 \mathrm{~m} / \mathrm{s}^{2}$ on OS at pass \#3 and $-81 \mathrm{~m} / \mathrm{s}^{2}$ on DS at pass \#1. Sign minus means that BWR chocks are moved towards entry side of the thick sheet rolling stand. In addition, there were numerous acceleration values from $25 \mathrm{~m} / \mathrm{s}^{2}$ to $65 \mathrm{~m} / \mathrm{s}^{2}$.

Analysis of movements of BWR with chocks in windows of housings during normal metal-in shows below given sequence that happens in $90 \%$ of normal metal-in cases:

- $\quad$ stage \#1 is when BWR chock is in the middle of housing window or pressed to any column of housing before rolling (fig.3, a);

- $\quad$ stage \#2 is when BWR chock moves against rolling direction during metal-in (start of rolling, unsteady rolling), hits column of housing and then there are numerous fading impacts of BWR chock against columns of housing on entry side and delivery side (fig.4, b);

- $\quad$ stage \#3 is when BWR chock is pressed to housing on entry side during steady rolling (fig.4, c);

- $\quad$ stage \#4 is when BWR chock hits column of housing on entry side during metalout (fig.3, d).

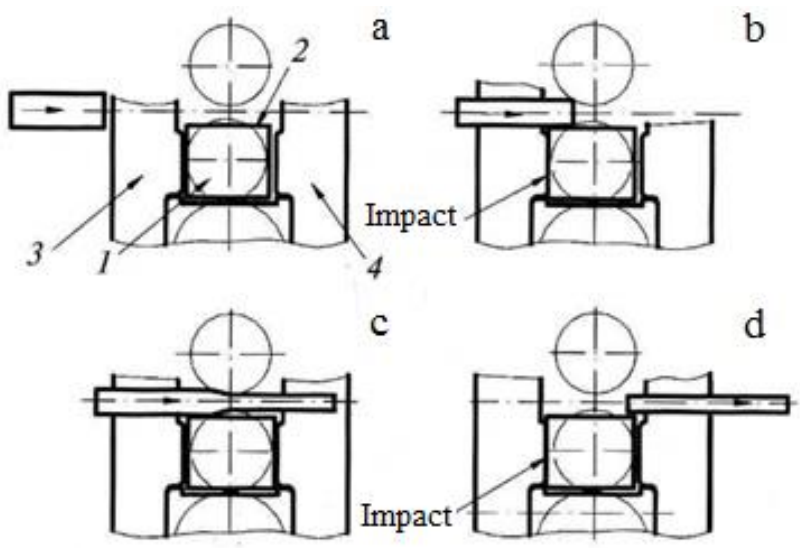

1 is BWR;

2 is BWR chock;

3 is column of housing on entry side;

4 is column of housing on delivery side

Fig. 3. Scheme of movements of BWR chock in housing window during rolling 

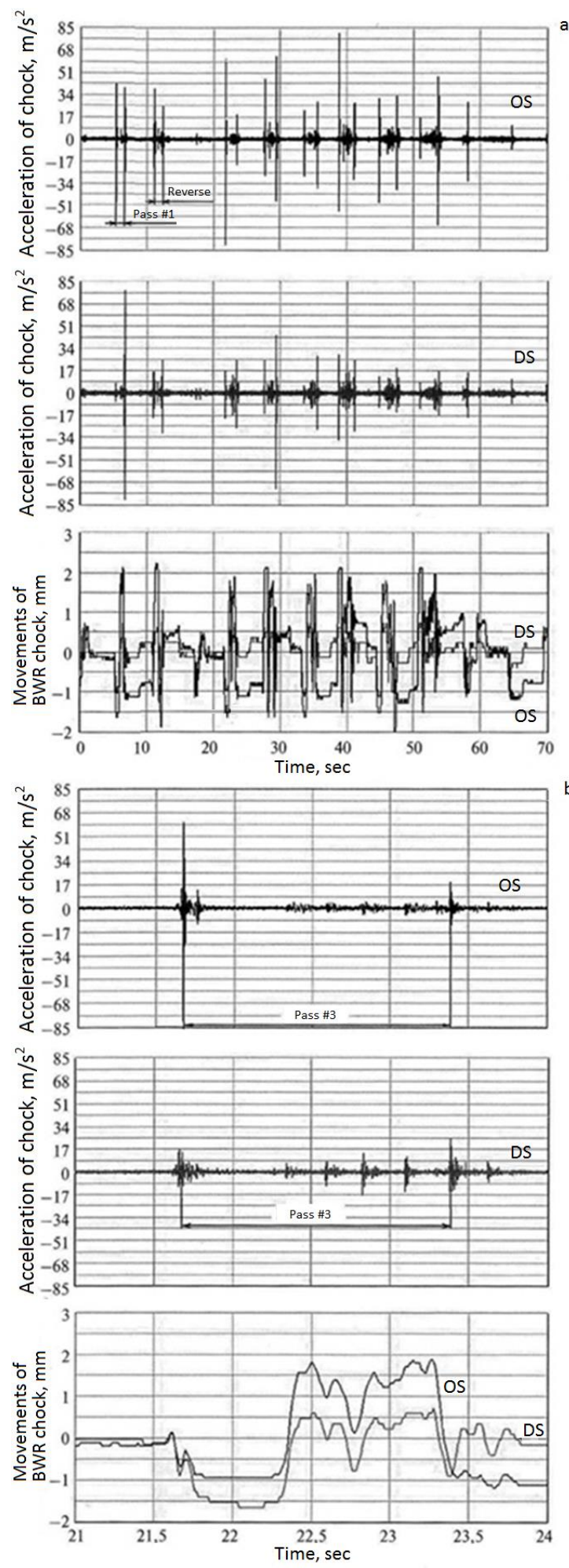

Fig. 4. Oscillogram of slab rolling (a) and part of that data during pass \#3 (b) 
Detailed visualization of BWR chocks horizontal accelerations, movements in housings windows and their impacts against housings (facing strips) is shown on fig. 5, where gap is horizontal changing distance between contact surfaces of chock (lining strap) and housing (facing strip). Results of the visualization with explanations are given in table 1 where shown values of forces of horizontal impacts of BWR chock against housing were calculated by usage of below given method (formulas from 1 to 6 , method is developed by authors of this paper). Sign minus of accelerations means that BWR chocks are moved towards entry side of the thick sheet rolling stand.

Table 1. Analysis results of passes \#4, 5 and 6 in roughing reversing 4-hi rolling stand of rolling mill 3000 and values of horizontal impact forces

\begin{tabular}{|c|c|c|c|c|c|c|c|}
\hline $\begin{array}{c}\# \\
n \\
\vdots \\
\tilde{a} \\
\tilde{n}\end{array}$ & $\frac{0}{0}$ & $\begin{array}{l}\text { Moment } \\
\text { of time, } \\
\text { sec }\end{array}$ & $\begin{array}{l}\text { Process } \\
\text { of } \\
\text { rolling }\end{array}$ & $\begin{array}{l}\text { Directions of } \\
\text { BWR chocks } \\
\text { movements from } \\
\text { DS and OS }\end{array}$ & 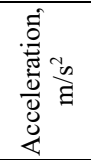 & 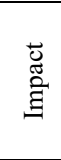 & $\begin{array}{c}\text { Horizontal forces of BWR } \\
\text { chocks impacts against } \\
\text { housings, } \mathrm{N}\end{array}$ \\
\hline \multirow{2}{*}{4} & DS & \multirow{2}{*}{27.744} & \multirow{2}{*}{$\begin{array}{l}\text { Metal- } \\
\text { in }\end{array}$} & Against RD & -15.39 & No & $\Longrightarrow$ \\
\hline & OS & & & Towards RD & 46.26 & Yes & $1.38 \cdot 10^{6}$ \\
\hline \multirow{2}{*}{4} & DS & \multirow{2}{*}{29.171} & \multirow{2}{*}{$\begin{array}{l}\text { Metal- } \\
\text { out }\end{array}$} & \multirow{2}{*}{ Against RD } & -72.95 & Yes & $1.58 \cdot 10^{6}$ \\
\hline & OS & & & & -47.19 & No & \\
\hline \multirow{2}{*}{5} & DS & \multirow{2}{*}{33.712} & \multirow{2}{*}{$\begin{array}{l}\text { Metal- } \\
\text { in }\end{array}$} & \multirow{2}{*}{ Against RD } & -7.44 & Yes & $\ll 1 \cdot 10^{6}$ \\
\hline & OS & & & & -28.27 & No & \\
\hline \multirow{2}{*}{6} & DS & \multirow{2}{*}{38.782} & \multirow{2}{*}{$\begin{array}{l}\text { Metal- } \\
\text { in }\end{array}$} & \multirow{2}{*}{ Against RD } & 29.88 & No & 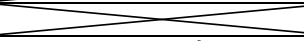 \\
\hline & OS & & & & 81.32 & Yes & $1.3 \cdot 10^{6}$ \\
\hline
\end{tabular}

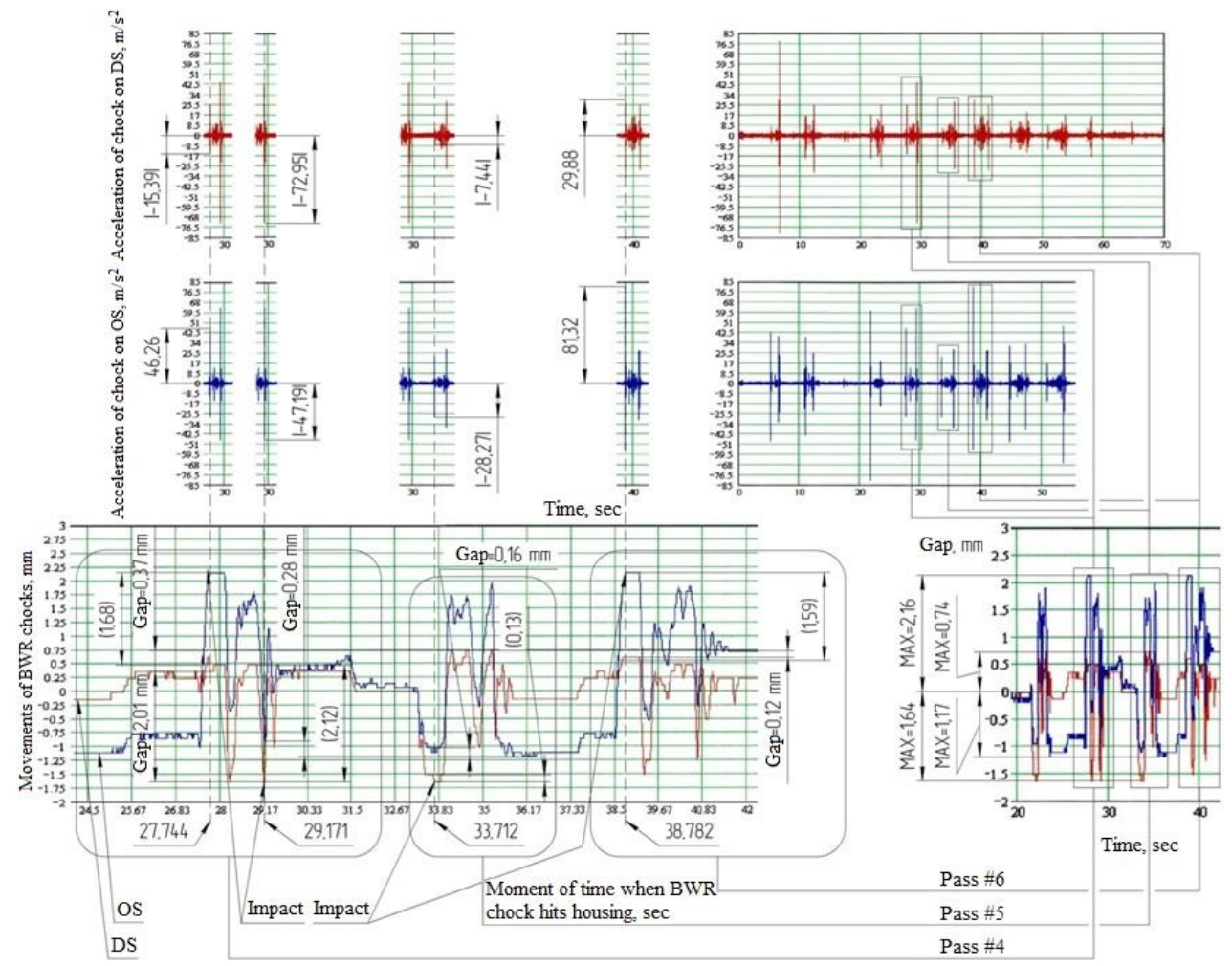

Fig. 5. Detailed visualization of BWR chocks horizontal accelerations, movements in housings windows and their impacts against housings at passes \#4, 5 and 6 
To define horizontal forces of rolls chocks impacts against housings (refer to table 1) of strip and thick sheet rolling stands when accelerations, movements and masses are known below given method based on BWR chocks is proposed. Force of horizontal impact of BWR chock against housing (as per Newton's second law):

$$
\mathrm{F}_{\text {dyn BWR }}=\mathrm{m} \cdot \mathrm{a}, \mathrm{N}
$$

where $\mathrm{m}$ is reduced active mass of BWR assembly with chocks, bearings, etc., $\mathrm{kg}$;

$a$ is horizontal acceleration of BWR chock, $\mathrm{m} / \mathrm{s}^{2}$.

Reduced active mass $\mathrm{m}$ of part of BWR assembly means that BWR assembly is considered as assembly with mass $\Sigma \mathrm{m}$ (sum of masses of all elements in the assembly). Impacts of BWR assembly against housings happen only by its chocks on DS and OS. Difference of horizontal accelerations of BWR chocks shows necessity to consider BWR assembly as element that consists of two parts where each part can hit housing. BWR assembly consists of two reduced active masses, namely $\mathrm{m}_{\mathrm{DS}}$ from DS and mos from OS.

During metal-in and steady rolling:

where $\mathrm{m}_{\text {slab }}$ is mass of slab, $\mathrm{kg}$.

$$
\Sigma \mathrm{m}+1 / 2 \cdot \mathrm{m}_{\text {slab }}=\mathrm{m}_{\mathrm{DS}}+\mathrm{m}_{\mathrm{OS}}, \mathrm{kg}
$$

During metal-out:

$$
\Sigma \mathrm{m}=\mathrm{m}_{\mathrm{DS}}+\mathrm{m}_{\mathrm{OS}}, \mathrm{kg}
$$

During metal-in and steady rolling when only one BWR chock hits housing and both BWR chocks are moved in one direction (based on BWR chock on OS):

$$
m_{O S}=\frac{\sum m+1 / 2 m_{\text {slab }}}{1+\frac{a_{O S}}{a_{D S}}}, \mathrm{~kg}
$$

where aos is horizontal acceleration of $\mathrm{mos}, \mathrm{m} / \mathrm{s}^{2}$;

$a_{D S}$ is horizontal acceleration of $\mathrm{m}_{\mathrm{DS}}, \mathrm{m} / \mathrm{s}^{2}$.

During metal-out when only one BWR chock hits housing and both BWR chocks are moved in one direction (based on BWR chock on DS):

$$
m_{D S}=\frac{\Sigma m}{1+\frac{a_{D S}}{a_{O S}}}, \mathrm{~kg}
$$

During metal-in and steady rolling when impact(s) against housing(s) happen(s) by: a) both BWR chocks simultaneously (rare case); b) only one BWR chock and both BWR chocks are moved in different directions (based on BWR chock on OS):

$$
m_{O S}=\frac{\sum m+1 / 2 m_{\text {slab }}}{2}, \mathrm{~kg}
$$

\section{Results}

Horizontal accelerations and displacements of WRs chocks define values of impact loads acting on housings (facing strips). Their biggest values act during metal-in and metal-out. 
Analysis of experimental oscillograms states that in $90 \%$ of normal metal-in cases during:

- metal-in and metal-out horizontal accelerations of BWR chock on DS are less than ones on OS;

- metal-in horizontal accelerations of BWR chock on OS are higher than ones on OS during metal-out;

- metal-in horizontal accelerations of BWR chock on DS are less than ones on DS during metal-out.

Done calculations of horizontal forces of BWR chocks impacts against housings provided execution of stress calculations of technical solutions for increase of rolling stands durability [7-12].

\section{Conclusions}

1. Technical aspects and methods of experimental measurements of horizontal accelerations and displacements of WRs chocks of rolling stands of thick sheet rolling mills 3000 and 3600 are shown. Maximum values of BWR chocks horizontal accelerations are around $82 \mathrm{~m} / \mathrm{s}^{2}$. In addition, there were numerous acceleration values from $25 \mathrm{~m} / \mathrm{s}^{2}$ to $65 \mathrm{~m} / \mathrm{s}^{2}$. The chocks are horizontally moved within gaps which permissible values are stated by rolling equipment producers (usually gap can be from $1.2 \mathrm{~mm}$ to $1.5 \mathrm{~mm}$ ). If gap is increased (e.g. due to wear of rolling equipment) from $1.0 \mathrm{~mm}$ to $3.5 \mathrm{~mm}$ it increases horizontal acceleration of WR chock by around $50 \%$.

2. Detailed analysis of obtained experimental measurements of horizontal accelerations and displacements of details of the thick sheet rolling mills is done. It helped to calculate horizontal forces of BWR chocks impacts against housings which maximum value is around $1.58 \cdot 10^{6} \mathrm{~N}$.

3. Sequence of horizontal movements of BWR with chocks in windows of housings during normal metal-in, steady rolling and metal-out is given.

4. It is recommended to use proposed method of horizontal forces calculation of BWR chocks impacts against housings to define ones of top WR chocks impacts against housings.

5. Usage of obtained experimental data and calculation of horizontal forces of WRs chocks impacts against housings provided execution of stress calculations of technical solutions for increase of rolling stands durability [3, 16, 17].

6. It is recommended to use experimental measurements of equipment details accelerations and movements on presses to improve their durability and quality of products [18-20].

\section{References}

1. V. Mazur, V. Artiukh, M.I. Matarneh. Procedia Engineering, 165, 1722-1730 (2016). DOI: 10.1016/j.proeng.2016.11.915.

2. V.V. Verenev, V.I. Bolshakov, A.M. Yunakov. Works, Dnepropetrovsk. 19, 346-358 (2009).

3. V. Artiukh, V. Mazur, A. Butyrin, EMMFT 2017. Advances in Intelligent Systems and Computing, 692, 212-219 (2018) DOI: https://doi.org/10.1007/978-3-319-70987-1_23.

4. L.V. Konovalov, Development of measures to stabilize work of main drive lines of work stands of thick sheet rolling mill 3000 of PJSC 'ILYICH iron and steel works' at project productivity and measures introduction. Stage \#3. Development of technical 
requirements on production and use of main details of rolling stands and proposals to technological instructions to produce heavy products. Scientific work report. (Moscow, VNIIMETMASH, 1992)

5. V.G. Artiukh, Loads and overloads in metallurgical machines (Mariupol, PSTU, 2008)

6. S. Nabeel, Engineering and Technology, 8 (12), 1461-1464 (2014)

7. V. Artiukh, V. Mazur, S. Kargin and N. Bushuev. MATEC Web of Conferences 170, 03011 (2018). doi.org/10.1051/matecconf/201817003011.

8. V. Artiukh, V. Mazur, S. Kargin and L. Zakharova. MATEC Web of Conferences 170, 03028 (2018). doi.org/10.1051/matecconf/201817003028.

9. V. Artiukh, V. Mazur, L. Shilova. MATEC Web of Conferences 106, 03002 (2017). DOI: $10.1051 /$ matecconf $/ 201710603002$.

10. V.G. Artiukh Basics of protection of metallurgical machines from breakdowns (Mariupol, PSTU, 2015)

11. A. Ishchenko, Metallurgy and mining industry, 2, 71-73 (2002)

12. V. Mazur, V. Artyukh, G. Artyukh, M. Takadzhi. Engineering Designer, 37, 1, 26-29 (2012).

13. A. Ishchenko etc. Study of dynamic loads acting on housings of rolling mill 3000 during rolling and development of solutions to optimize work of rolling mill (Mariupol, PSTU, 2006)

14. A. Ishchenko, etc. Steel, 5, 63-65 (2003)

15. A. Ishchenko et.al. Steel in Translation, 2009. 39(5), pp. 428-430 (2009).

16. V. Artiukh, T. Raimberdiyev, V. Mazur. MATEC Web of Conferences, 53, 01039 (2016) DOI: http://dx.doi.org/10.1051/matecconf/20165301039.

17. E. Sorochan, V. Artiukh, B. Melnikov, MATEC Web of Conferences, 73, 04009 (2016) DOI: http://dx.doi.org/10.1051/matecconf/20167304009.

18. V.V. Kukhar, O.V. Vasylevskyi. Metallurgical and Mining Industry, 2014, 3, 71-78 (2014)

19. D. Kitaeva, About the Volume Forming of Aluminium Details in Superplasticity Conditions, METAL, 23rd International Conf. on Metallurgy and Materials, Conf. Proc. 347-352 (2014)

20. L.I. Ogorodov. Mechanics of Composite Materials, 30. 6, 771-780 (1990) 